\title{
Remoção de demanda química de oxigênio e nitrogênio total Kjeldahl de efluente de indústria de vegetais congelados por Reator em Batelada Sequencial
}

\author{
Chemical Oxygen Demand and Total Kjeldahl Nitrogen removal of frozen \\ vegetables industry wastewater by Sequential Batch Reactor
}

\begin{abstract}
Thaís Luciana Betto
Bacharel em Química. Mestre em Engenharia pelo Programa de Pós Graduação em Engenharia da Universidade de Passo Fundo (UPF) - Passo Fundo (RS), Brasil.

\section{Marcelo Hemkemeier}

Químico Industrial. Doutor em Engenharia de Alimentos pela Universidade Estadual de Campinas (UNICAMP) - Campinas (SP), Brasil.

Professor do Programa de Pós Graduação em Engenharia Mecânica da UPF - Passo Fundo (RS), Brasil.
\end{abstract}

Paulo Roberto Koetz

Engenheiro Químico. Doutor em Recursos Hídricos e Saneamento Ambiental pelo Instituto de Pesquisas Hidráulicas da

Universidade Federal do Rio Grande do Sul (UFRGS) - Porto Alegre (RS), Brasil.

\section{Resumo}

O objetivo deste trabalho foi estudar o tratamento biológico de efluente de indústria de vegetais congelados em Reator em Batelada Sequencial (RBS), verificando o efeito da concentração de Sólidos Suspensos Voláteis (SSV), Demanda Química de Oxigênio inicial (DQO) e aeração na remoção biológica de carbono e nitrogênio, a fim de obter um efluente tratado que atenda aos padrões de lançamento recomendados pela legislação ambiental brasileira. Nesta pesquisa, o tratamento dos efluentes foi feito em um RBS, utilizando concentração de SSV variando entre $2000 \mathrm{mg} . \mathrm{L}^{-1}$ e $4000 \mathrm{mg} . \mathrm{L}^{-1}, \mathrm{DQO}, \mathrm{variando}$ entre $300 \mathrm{mg} \cdot \mathrm{L}^{-1}$ e $600 \mathrm{mg} \cdot \mathrm{L}^{-1}$, e quantidade de aeração variando entre $3 \mathrm{~L}$. $\mathrm{min}^{-1}$ e $6 \mathrm{~L}$. $\mathrm{min}^{-1}$. Os resultados mostram que a maior eficiência de remoção para DQO foi de $88 \%$, e para nitrogênio total Kjeldahl (NTK) foi de $74,9 \%$. As condições otimizadas para remoção de DQO e NTK do efluente estudado foram: DQO inicial de $600 \mathrm{mg} \cdot \mathrm{L}^{-1}$, aeração de 4,5 L.min ${ }^{-1}$ e concentração de SSV de $2000 \mathrm{mg} \cdot \mathrm{L}^{-1}$.

Palavras-chave: tratamento biológico de efluentes; RBS; indústria de alimentos.

\begin{abstract}
The objective of this work was to study the biological wastewater treatment from frozen vegetables industry in sequential batch reactor (SBR), verifying the effect of the volatile suspended solids (VSS) concentration, initial Chemical Oxygen Demand (iCOD) and aeration to remove organic carbon and nitrogen in order to obtain a treated wastewater that meets discharge standards recommended by the Brazilian environmental legislation. In this study, the treatment of wastewaters was done in an SBR using VSS concentration ranging from $2000 \mathrm{mg} \mathrm{L}^{-1}$ and $4000 \mathrm{mg} \cdot \mathrm{L}^{-1}$, iCOD ranging from $300 \mathrm{mg} \cdot \mathrm{L}^{-1}$ and $600 \mathrm{mg}^{\mathrm{L}} \mathrm{L}^{-1}$, and aeration ranging between $3 \mathrm{~L}$. min ${ }^{-1}$ and $6 \mathrm{~L}$. $\mathrm{min}^{-1}$. The results show that the major removal efficiency for COD was 88\%, and for Total Kjeldahl Nitrogen (TKN) was 74,9\%. The optimized conditions for COD and TKN removal of the studied wastewater were: initial COD of $600 \mathrm{mg} \cdot \mathrm{LL}^{-1}$, aeration of $4.5 \mathrm{~L}^{\mathrm{m}} \mathrm{min}^{-1}$ and VSS concentration of $2000 \mathrm{mg} . \mathrm{L}^{-1}$.
\end{abstract}

Keywords: biologic wastewaters treatment; SBR; foods industry.

\section{Introdução}

A indústria de alimentos é um dos maiores setores industriais do mundo, e pode causar grave poluição orgânica se projetada ou operada sem dar atenção suficiente ao meio ambiente. Entre os problemas ambientais do setor de alimentos estão o alto consumo de água e a geração de efluentes líquidos com alta carga orgânica, além da geração de um grande volume de lodo nas estações com tratamento 
biológico (RAMJEAWON, 2000). A indústria de vegetais congelados é um exemplo desse setor, no qual as diversas operações realizadas geram um grande volume de efluente com uma elevada carga orgânica.

O Reator em Batelada Sequencial (RBS) é um sistema de lodo ativado para tratamento de efluentes. Neste sistema, o efluente é adicionado a um reator em batelada, tratado para remover componentes indesejáveis, e então descarregado. As etapas de equalização, aeração e clarificação podem ser realizadas em um único reator (EPA, 1999).

O RBS tem se mostrado particularmente adequado para o tratamento de água residuária, que é caracterizada pelo alto teor de nutrientes e frequentes mudanças na composição (AKIM \& UGURLU, 2005, KIM et al., 2008). Este reator apresenta vantagens e desvantagens em relação aos métodos convencionais de lodos ativados. Entre as vantagens estão: forma simplificada de construção; facilidade de colocação de equipamentos com instalações tecnicamente simples; grande flexibilização, no que diz respeito à variação das cargas e vazões; funcionamento relativamente simplificado; e boa decantabilidade do lodo (WILDERER et al., 1997; VAN HAANDEL \& MARAIS, 1999 apud COSTA, 2005). Ainda como vantagens, pode-se citar o mínimo espaço requerido, a facilidade de gestão e a possibilidade de modificações durante a fase experimental (AKIN \& UGURLU, 2005). Como desvantagem, Costa (2005), diz que o descarte do efluente tratado é feito de forma pontual, a cada término do ciclo, o que acarreta um grande choque de carga para o corpo receptor.

A utilização de Reatores em Batelada Sequencial (RBS) é uma das possíveis alternativas tecnológicas capazes de proporcionar as variações das condições ambientais necessárias para a ocorrência dos processos de nitrificação/desnitrificação e biodesfosfatação (CYBIS \& PICKBRENNER, 2000).

O objetivo deste trabalho foi estudar o tratamento biológico de efluente de indústria de vegetais congelados em RBS, verificando o efeito da concentração de sólidos suspensos voláteis (SSV), demanda química de oxigênio inicial (DQO) e aeração na remoção biológica de carbono e nitrogênio, a fim de obter um efluente tratado que atendesse aos padrões de lançamento recomendados pela legislação ambiental brasileira.

\section{Metodologia}

\section{Delimitação do trabalho}

Os efluentes foram coletados em uma indústria de vegetais congelados da região de Passo Fundo (RS). A indústria opera com uma variada gama de produtos vegetais congelados. O processamento depende de fatores sazonais (período de safra), mercado, entre outros.

O efluente passa por um processo físico-químico de tratamento, a partir do qual foi coletado efluente para uso no RBS em escala laboratorial.

\section{Visita à indústria}

O processo de coleta de dados iniciou com visitas à unidade industrial, onde foram levantadas todas as atividades desenvolvidas, bem como quais os tipos de vegetais que estariam sendo processados no período, os sistemas de tratamento de efluentes, entre outros. Ainda, foram feitas coletas do efluente bruto (sem nenhum tratamento), para que fosse feita a caracterização desses efluentes.

\section{Caracterização dos efluentes coletados}

Os efluentes coletados na indústria foram caracterizados em termos de DQO, Nitrogênio Total Kjeldahl (NTK), Fósforo Total ( $\left.\mathrm{P}_{\text {Total }}\right)$, Sólidos Suspensos Totais (SST), Sólidos Sedimentáveis (SSed), pH e Temperatura (T). As análises foram feitas de acordo com os métodos analíticos descritos em APHA (2000).

\section{Tratamento Biológico dos efluentes em Reator em Batelada Sequencial}

\section{Reator em Batelada Sequencial}

O RBS aerado foi construído no formato cilíndrico em vidro borossilicato, em escala laboratorial, com diâmetro de $10 \mathrm{~cm}$, altura de $60 \mathrm{~cm}$ e capacidade total de 3,5 L. A alimentação e a descarga foram feitas manualmente. A aeração foi feita por compressor de ar e a vazão de ar foi controlada por um rotâmetro. A Figura 1 mostra o esquema do RBS utilizado para a pesquisa.

Variáveis do RBS

Para os cálculos estatísticos foi utilizado um planejamento fatorial $2^{3}$ (Tabela 1), com as seguintes variáveis independentes:

a) $X_{1}=$ Concentração de Sólidos Suspensos Voláteis (SSV) no rea-

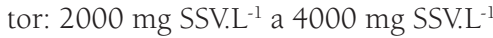

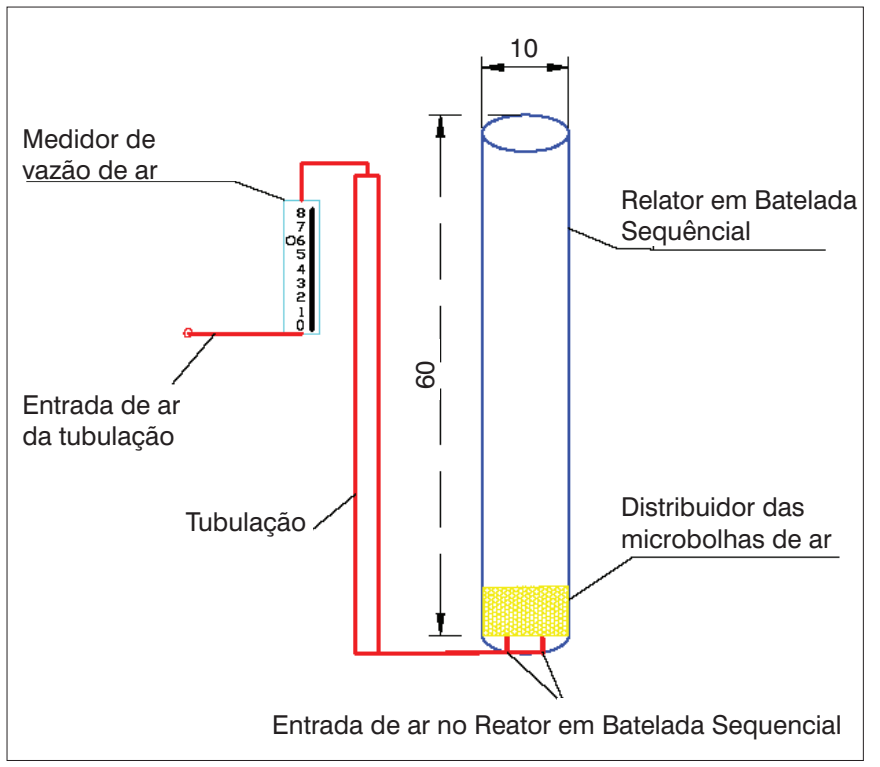

Figura 1 - Esquema de montagem do reator em Batelada Sequencial em escala laboratorial. 
Tabela 1 - Matriz dos valores codificados e níveis das variáveis utilizadas no planejamento fatorial $2^{3}$.

\begin{tabular}{lcccccc}
\multirow{2}{*}{ Experimentos } & \multicolumn{3}{c}{ Variáveis Codificadas } & \multicolumn{3}{c}{ Variáveis Reais } \\
\cline { 2 - 7 } & $\mathrm{X}_{1}$ & $\mathrm{X}_{2}$ & $\mathrm{X}_{3}$ & $\mathrm{X}_{1}$ & $\mathrm{X}_{2}$ & $\mathrm{X}_{3}$ \\
\hline & -1 & -1 & -1 & 2000 & 300 & 3 \\
2 & +1 & -1 & -1 & 4000 & 300 & 3 \\
3 & -1 & +1 & -1 & 2000 & 600 & 3 \\
4 & +1 & +1 & -1 & 4000 & 600 & 3 \\
\hline 5 & -1 & -1 & +1 & 2000 & 300 & 6 \\
\hline 6 & +1 & -1 & +1 & 4000 & 300 & 6 \\
7 & -1 & +1 & +1 & 2000 & 600 & 6 \\
\hline 8 & +1 & +1 & +1 & 4000 & 600 & 6 \\
\hline 9 & 0 & 0 & 0 & 3000 & 450 & 4,5 \\
\hline 10 & $+1,68$ & 0 & 0 & 4700 & 450 & 4,5 \\
11 & 0 & $-1,68$ & 0 & 3000 & 200 & 4,5 \\
12 & 0 & 0 & $+1,68$ & 3000 & 450 & 7,0 \\
13 & 0 & 0 & $-1,68$ & 3000 & 450 & 2,0 \\
14 & 0 & $+1,68$ & 0 & 3000 & 700 & 4,5 \\
15 & $-1,68$ & 0 & 0 & 1300 & 450 & 4,5 \\
\hline
\end{tabular}

$\mathrm{X}_{1}$ : concentração de Sólidos Suspensos Voláteis $\left(\mathrm{mg} \cdot \mathrm{L}^{-1}\right) ; \mathrm{X}_{2}$ : demanda química inicial (mg.L'-1); $\mathrm{X}_{3}$ : aeração $\left(\right.$ L. $\left.\mathrm{min}^{-1}\right)$

b) $\mathrm{X}_{2}=$ Concentração de $\mathrm{DQO}_{\mathrm{i}}: 300 \mathrm{mg} \cdot \mathrm{L}^{-1}$ a $600 \mathrm{mg} \cdot \mathrm{L}^{-1}$

c) $\mathrm{X}_{3}=$ Aeração: 3 L.min ${ }^{-1}$ a 6 L.min min $^{-1}$.

As variáveis de resposta foram a remoção de DQO e NTK.

Os experimentos foram feitos de forma aleatorizada, em triplicata. Os dados obtidos foram analisados estatisticamente.

Inoculação dos Reatores

A inoculação foi realizada com lodo de uma estação de tratamento de efluentes de indústria de vegetais congelados, adaptado para utilização no RBS em escala laboratorial.

Preparação do efluente e ajuste do lodo

O efluente proveniente do processamento do brócolis, após passar pelo tratamento físico químico, foi utilizado para os experimentos com o RBS em escala laboratorial. A produção de brócolis é a mais representativa dentro da rotina produtiva da indústria que forneceu o efluente, justificando tal escolha. O efluente a ser tratado pelo RBS em escala laboratorial (antes de ser colocado no reator) foi analisado em cada recebimento de efluente, em termos de pH, DQO, fósforo total, Nitrogênio Total Kjeldahl, decantabilidade, sólidos suspensos totais e sólidos suspensos voláteis.

A cada início de batelada, antes do enchimento do reator, a concentração da DQO inicial foi ajustada, por diluição, para 300, 450 ou 600 mg.L $L^{-1}$, e a concentração de SSV foi ajustada para 2000, $3000 \mathrm{ou} 4000 \mathrm{mg} . \mathrm{L}^{-1}$, conforme planejamento fatorial. O ajuste da concentração de SSV foi feito através da comparação da leitura em espectrofotômetro da turbidez a $600 \mathrm{~nm}$ de uma amostra retirada do reator, diluída cinco vezes, com a curva padrão de sólidos suspensos totais.

\section{Operação do Reator em Batelada Sequencial}

O reator foi operado em sistema sequencial em batelada aeróbio, com ciclos de reação de seis horas, que foi o tempo estimado para utilização do RBS em indústrias. As fases de operação foram:

a) Enchimento: o efluente foi adicionado manualmente no reator. $\mathrm{O}$ volume de efluente adicionado foi de dois litros. Esta fase ocorreu instantaneamente.

b) Reação: o líquido foi agitado e aerado para que ocorressem as reações biológicas. Após um minuto de aeração, foi retirada uma amostra de efluente (efluente inicial) com a qual foram feitas análises de $\mathrm{pH}, \mathrm{DQO}$, fósforo, nitrogênio, temperatura (ambiente e no reator). Após seis horas de aeração (final da fase de reação), outra amostra de efluente (efluente final) foi retirada para que fossem feitas as análises de $\mathrm{pH}$, temperatura, DQO, fósforo e nitrogênio. Para as análises de DQO, nitrogênio e fósforo, a amostra retirada do reator foi filtrada.

c) Sedimentação: a agitação foi desativada por cerca de 40 min para que o lodo decantasse.

d) Descarga do efluente: o efluente foi retirado do reator através dos pontos de retirada de amostra existentes no reator. Esta fase ocorreu instantaneamente.

e) Repouso: a biomassa foi mantida em aeração constante, até a próxima batelada (cerca de $17 \mathrm{~h}$ ).

Após a análise dos efluentes tratados por RBS foi feito o cálculo da eficiência do mesmo na remoção de nitrogênio e DQO. Esta eficiência foi calculada para o efluente retirado do reator após um minuto e após seis horas de reação.

\section{Determinações Analíticas}

A análise de DQO foi feita em refluxo fechado, através do método colorimétrico, no qual se utiliza o dicromato de potássio como agente colorimétrico (APHA, 2000).

O NTK foi determinado por digestão e destilação da amostra através do digestor de nitrogênio Kjeldahl (APHA, 2000).

A análise de $\mathrm{P}_{\text {Total }}$ foi feita pelo método colorimétrico utilizando-se reagente de Armstrong e ácido ascórbico (APHA, 2000).

Os SST foram determinados por gravimetria (filtração em papel). A concentração dos SSV foi obtida a $180^{\circ} \mathrm{C}$ (APHA, 2000).

Os SSed foram determinados pelo método de sedimentação, utilizando-se cones de Imhoff (APHA, 2000).

A análise de $\mathrm{pH}$ foi feita através do método eletrométrico.

A análise de Temperatura ( $\mathrm{T}$ ) foi feita através de um termômetro com escala de -10 a $110^{\circ} \mathrm{C}$. 


\section{Resultados}

\section{Caracterização de efluentes de indústria de vegetais congelados}

A Tabela 2 apresenta os resultados da caracterização de efluentes brutos (sem nenhum tratamento), coletados na entrada da ETE da indústria que forneceu os efluentes, para diferentes vegetais processados.

\section{Experimentos com Reatores em Batelada Sequencial}

A média de pH durante a realização dos experimentos com o RBS foi 7,13 , enquanto que a temperatura do efluente no reator ficou em média $18,8^{\circ} \mathrm{C}$ e a temperatura ambiente média foi de $17,5^{\circ} \mathrm{C}$.

As Tabelas 3 e 4 mostram a concentração média de DQO e de NTK após seis horas de reação, a eficiência de remoção do RBS para esses poluentes nos experimentos realizados. Estes experimentos foram comparados com a Resolução do CONSEMA

Tabela 2 - Caracterização dos efluentes brutos obtidos no processamento de brócolis, cenoura, ervilha e couve-flor.

\begin{tabular}{lccccccc} 
Amostra & $\begin{array}{c}\text { DQO } \\
\left(\mathrm{mg} \cdot \mathrm{L}^{-1}\right)\end{array}$ & $\begin{array}{c}\mathrm{PT} \\
\left(\mathrm{mg} \cdot \mathrm{L}^{-1}\right)\end{array}$ & $\begin{array}{c}\mathrm{NTK} \\
\left(\mathrm{mg} \cdot \mathrm{L}^{-1}\right)\end{array}$ & $\begin{array}{c}\mathrm{SSed} \\
\left(\mathrm{mg} \cdot \mathrm{L}^{-1}\right)\end{array}$ & $\begin{array}{c}\mathrm{SST} \\
\left(\mathrm{mg} \cdot \mathrm{L}^{-1}\right)\end{array}$ & $\mathrm{pH}$ & $\begin{array}{c}\mathrm{T} \\
\left({ }^{\circ} \mathrm{C}\right)\end{array}$ \\
$\begin{array}{l}\text { Brócolis } \\
(19 / 09 / 08)\end{array}$ & 3749 & 4,5 & 91 & 11 & 3627 & 6,0 & 29 \\
$\begin{array}{l}\text { Brócolis } \\
(17 / 10 / 08)\end{array}$ & 2129 & 2,4 & 40 & 5 & 631 & 5,4 & 21 \\
$\begin{array}{l}\text { Cenoura } \\
(27 / 11 / 08)\end{array}$ & 5773 & 2,7 & 41 & 42 & 2830 & - & - \\
$\begin{array}{l}\text { Ervilha/ } \\
\text { brócolis } \\
(16 / 12 / 08)\end{array}$ & 1742 & 1,29 & 44 & 16,5 & 520 & - & - \\
$\begin{array}{l}\text { Couve-flor } \\
(04 / 06 / 09)\end{array}$ & 2087 & 0,86 & 13,4 & 1,5 & 790 & - & - \\
\hline
\end{tabular}

DQO: demanda química de oxigênio; $P_{\text {Total }}$ Fósforo Total; NTK: nitrogênio total Kjeldahl; SSed: Sólidos Sedimentáveis; SST: sólidos suspensos totais; T: temperatura. $\mathrm{n}^{\circ} 128 / 2006$ para a faixa de vazão menor que $100 \mathrm{~m}^{3} \cdot \mathrm{d}^{-1}$, que é a vazão da indústria que forneceu o efluente.

\section{Análise estatística dos dados obtidos}

Remoção de demanda química de oxigênio

A Tabela 5 apresenta os resultados da ANOVA (Análise de Variância) para a variável remoção de DQO. Ao se utilizar um nível de significância de 10\% (p<0,1), os fatores Concentração de SSV (L), DQO (L e Q) e a interação entre $\mathrm{DQO}_{\mathrm{i}}(\mathrm{L})$ e aeração (L) foram significativos.

A Figura 2 apresenta a superfície de resposta para remoção de DQO, utilizando as variáveis: (a) aeração e $\mathrm{DQO}_{i}$ e (b) $\mathrm{DQO}_{i}$ e Concentração de SSV.

Remoção de NTK

A Tabela 6 apresenta a ANOVA (análise de variância) para a remoção de NTK. A análise mostrou que apenas o fator Aeração (Q) foi significativo $(\mathrm{p}<0,1)$.

A Figura 3 apresenta a superfície de resposta para remoção de NTK, utilizando as variáveis: (a) aeração e $\mathrm{DQO}_{\mathrm{i}}$ e (b) $\mathrm{DQO}_{\mathrm{i}}$ e Concentração de SSV.

\section{Discussão}

\section{Caracterização de efluentes de indústria de vegetais congelados}

Os efluentes de indústrias de vegetais congelados variam a cada tipo de vegetal processado, podendo variar até mesmo quando o mesmo vegetal é processado em datas diferentes, como ocorreu com o efluente de brócolis coletado no dia 19/09/2008 e no dia 17/10/2008. Essa variabilidade

Tabela 3 - Concentração média de demanda química de oxigênio após seis horas de reação, eficiência de remoção do Reator em Batelada Sequencial para demanda química de oxigênio em cada experimento e comparação com a legislação ambiental do Rio Grande do Sul.

\begin{tabular}{|c|c|c|c|c|c|c|c|}
\hline \multirow{2}{*}{ Experimentos } & \multicolumn{3}{|c|}{ Variáveis } & \multirow{2}{*}{$\begin{array}{l}\mathrm{CDQO}_{f} \\
\left(\mathrm{mg} \cdot \mathrm{L}^{-1}\right)\end{array}$} & \multirow{2}{*}{$\begin{array}{l}E_{D Q O} \\
(\%)\end{array}$} & \multirow{2}{*}{ Desvio Padrão } & \multirow{2}{*}{$\begin{array}{l}\text { Limite legislação } \\
\text { (mg. L-1 DQO) }\end{array}$} \\
\hline & $\mathrm{X}_{1}$ & $\mathrm{X}_{2}$ & $\mathrm{X}_{3}$ & & & & \\
\hline 1 & $2000(-1)$ & $300(-1)$ & $3(-1)$ & 66,1 & 77,97 & 57,4 & 360 \\
\hline 2 & $4000(+1)$ & $300(-1)$ & $3(-1)$ & 92,0 & 69,3 & 3,15 & 360 \\
\hline 3 & $2000(-1)$ & $600(+1)$ & $3(-1)$ & 71,9 & 88,0 & 53,11 & 360 \\
\hline 4 & $4000(+1)$ & $600(+1)$ & $3(-1)$ & 80,7 & 86,57 & 91,04 & 360 \\
\hline 5 & $2000(-1)$ & $300(-1)$ & $6(+1)$ & 93,2 & 68,9 & 7,86 & 360 \\
\hline 6 & $4000(+1)$ & $300(-1)$ & $6(+1)$ & 88,9 & 70,33 & 4,75 & 360 \\
\hline 7 & $2000(-1)$ & $600(+1)$ & $6(+1)$ & 115,4 & 80,77 & 64,35 & 360 \\
\hline 8 & $4000(+1)$ & $600(+1)$ & $6(+1)$ & 72,1 & 88,0 & 33,69 & 360 \\
\hline 9 & $3000(0)$ & $450(0)$ & $4,5(0)$ & 87,9 & 80,47 & 4,23 & 360 \\
\hline 10 & $4700(+1,68)$ & $450(0)$ & $4,5(0)$ & 90,4 & 80,0 & 0,35 & 360 \\
\hline 11 & $3000(0)$ & $200(-1,68)$ & $4,5(0)$ & 86,4 & 57,0 & 0,43 & 360 \\
\hline 12 & $3000(0)$ & $450(0)$ & $7,0(+1,68)$ & 93,7 & 79,0 & 0,25 & 360 \\
\hline 13 & $3000(0)$ & $450(0)$ & $2,0(-1,68)$ & 95,8 & 79,0 & 1,13 & 360 \\
\hline 14 & $3000(0)$ & $700(+1,68)$ & $4,5(0)$ & 94,0 & 87,0 & 0,74 & 360 \\
\hline 15 & $1300(-1,68)$ & $450(0)$ & $4,5(0)$ & 93,9 & 79,0 & 0,10 & 360 \\
\hline
\end{tabular}

$\mathrm{X}_{1}$ : concentração de Sólidos Suspensos Voláteis $\left(\mathrm{mg}^{\mathrm{L}} \mathrm{L}^{-1}\right) ; \mathrm{X}_{2}$ : demanda química de oxigênio inicial $\left(\mathrm{mg}^{\mathrm{L}} \mathrm{L}^{-1}\right)$; $\mathrm{X}_{3}$ : aeração (L.min-1); $\mathrm{CDQO}$ : Concentração de DQO final (após $6 \mathrm{~h}$ de reação); $\mathrm{E}_{\mathrm{DQO}}$ : Eficiência de remoção de DQO 
Tabela 4 - Concentração média de nitrogênio total Kjeldahl após seis horas de reação, eficiência de remoção do Reator em Batelada Sequencial para nitrogênio total Kjeldahl em cada experimento e comparação com a legislação ambiental brasileira.

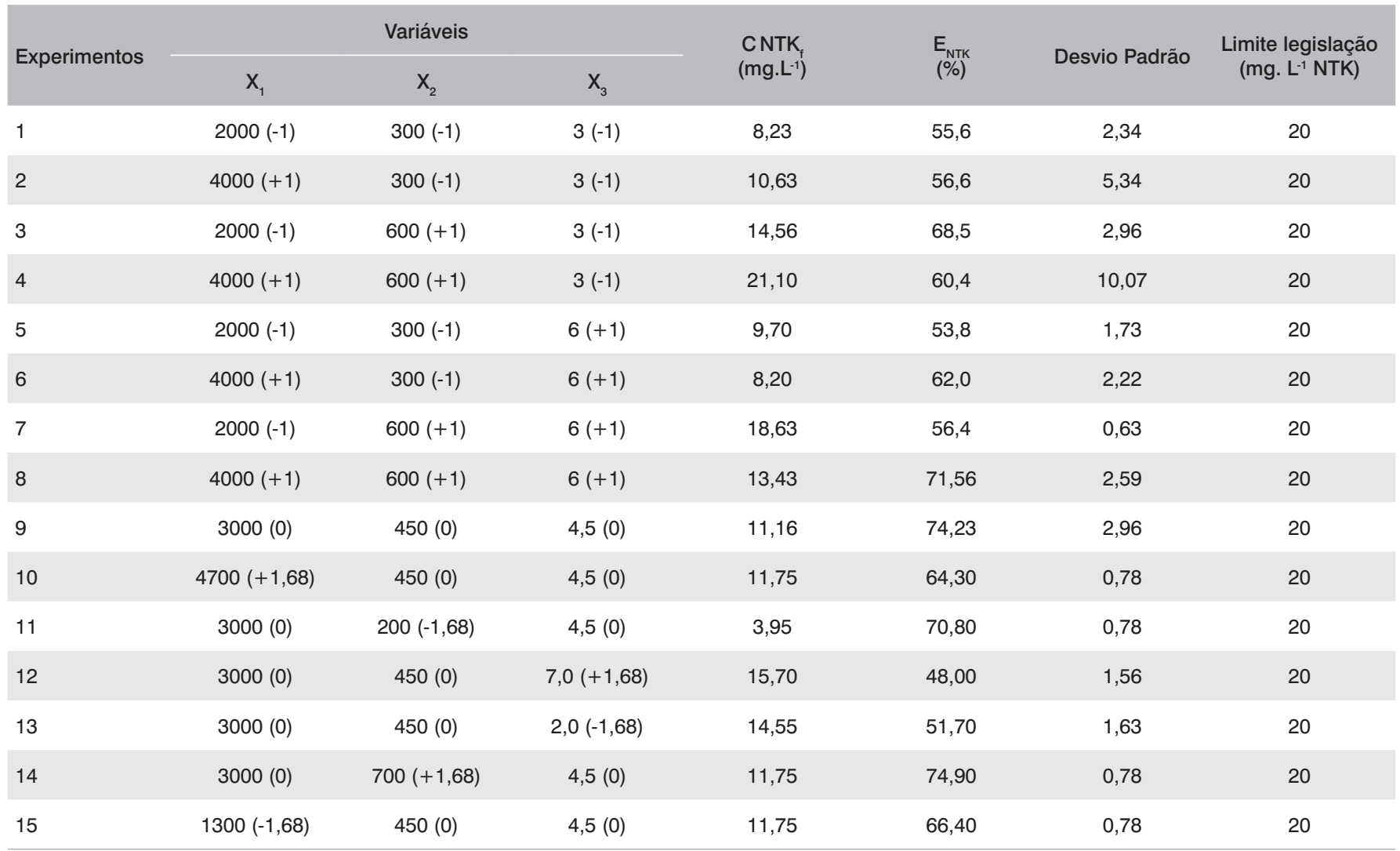

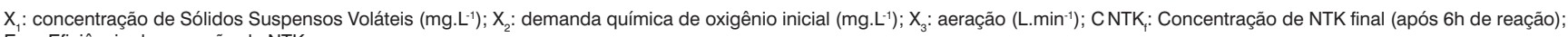
$\mathrm{E}_{\mathrm{NTK}}:$ Eficiência de remoção de NTK.

Tabela 5 - ANOVA para remoção de demanda química de oxigênio.

\begin{tabular}{lccccc}
\hline FATOR & SS & Df & MS & F & Valor $p$ \\
$\begin{array}{l}\text { (1) Concentração } \\
\text { de SSV (L) }\end{array}$ & 10,190 & 1 & 10,190 & 11,803 & 0,075279 \\
$\begin{array}{l}\text { Concentração de } \\
\text { SSV (Q) }\end{array}$ & 0,268 & 1 & 0,268 & 0,310 & 0,633701 \\
\hline (2) DQO (L) & 1032,119 & 1 & 1032,119 & 1195,505 & 0,000835 \\
\hline DQO (Q) & 89,029 & 1 & 89,029 & 103,123 & 0,009558 \\
\hline (3) Aeração (L) & 0,983 & 1 & 0,983 & 1,138 & 0,397729 \\
\hline Aeração (Q) & 1,196 & 1 & 1,196 & 1,386 & 0,360270 \\
\hline 1L por 2L & 0,792 & 1 & 0,792 & 0,917 & 0,439312 \\
\hline 1L por 3L & 5,865 & 1 & 5,865 & 6,794 & 0,121042 \\
\hline 2L por 3L & 11,400 & 1 & 11,400 & 13,205 & 0,068086 \\
\hline Falta de ajuste & 16,480 & 5 & 3,296 & 3,818 & 0,220494 \\
\hline Erro puro & 1,727 & 2 & 0,863 & & \\
\hline Total SS & 1175,640 & 16 & & & \\
\hline
\end{tabular}

SS: soma dos quadrados; Df: graus de liberdade; MS: média dos quadrados; F: distribuicão de Fischer; p: nível de significância; L: linear; Q: quadrático; DQO: demanda química inicial; SSV: Sólidos Suspensos Voláteis.
Tabela 6 - ANOVA para remoção de nitrogênio total Kjeldahl.

\begin{tabular}{lccccc}
\hline FATOR & SS & Df & MS & F & Valor $p$ \\
$\begin{array}{l}\text { (1) Concentração } \\
\text { de SSV (L) }\end{array}$ & 11,699 & 1 & 11,6985 & 0,17402 & 0,717074 \\
\hline $\begin{array}{l}\text { Concentração de } \\
\text { SSV (Q) }\end{array}$ & 131,311 & 1 & 131,3114 & 1,95336 & 0,297077 \\
\hline (2) DQO (L) & 94,371 & 1 & 94,3712 & 1,40385 & 0,357793 \\
\hline DQO (Q) & 6,899 & 1 & 6,8987 & 0,10262 & 0,779076 \\
\hline (3) Aeração (L) & 0,938 & 1 & 0,9384 & 0,01396 & 0,916743 \\
\hline Aeração (Q) & 902,125 & 1 & 902,1247 & 13,41981 & 0,067103 \\
\hline 1L por 2L & 0,569 & 1 & 0,5689 & 0,00846 & 0,935088 \\
\hline 1L por 3L & 116,027 & 1 & 116,0272 & 1,72600 & 0,319389 \\
\hline 2L por 3L & 2,494 & 1 & 2,4939 & 0,03710 & 0,865050 \\
\hline Falta de ajuste & 86,492 & 5 & 17,2983 & 0,25733 & 0,904114 \\
\hline Erro puro & 134,447 & 2 & 67,2233 & & \\
\hline Total SS & 1408,061 & 16 & & & \\
\hline
\end{tabular}

SS: soma dos quadrados; Df: graus de liberdade; MS: média dos quadrados; F: distribuição de Fischer; p: nível de significância; L: linear; Q: quadrático; DQO: demanda química inicial; SSV: Sólidos Suspensos Voláteis. 

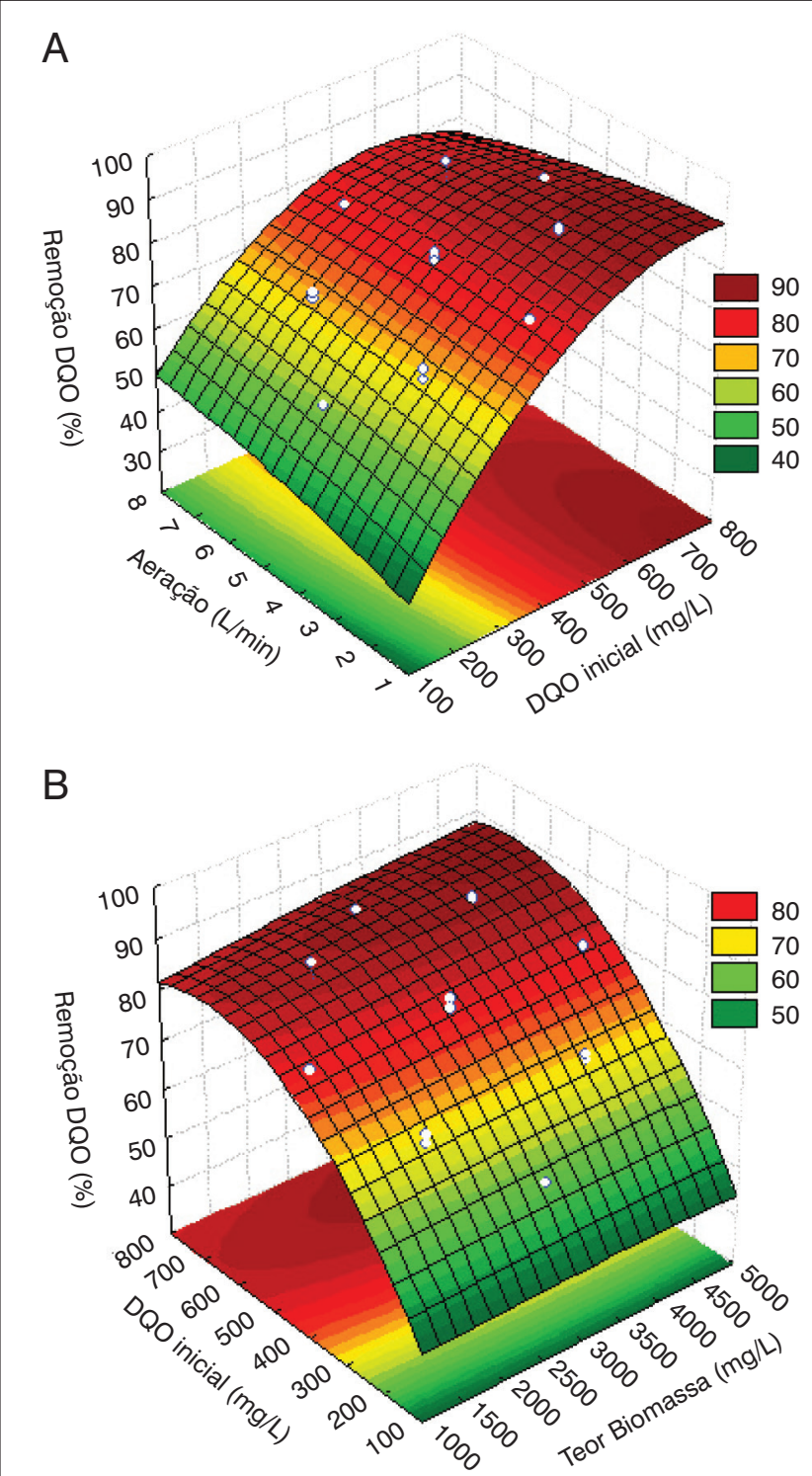

Figura 2 - Superfície de resposta para remoção de demanda química de oxigênio, utilizando as variáveis: $(A)$ aeração e demanda química de oxigênio inicial e (B) demanda química de oxigênio inicial e concentração de Sólidos Suspensos Voláteis.

dos efluentes causa uma dificuldade em encontrar um sistema de tratamento que se adapte às grandes variações dos efluentes gerados e que seja eficiente para os efluentes dos diversos vegetais processados. O RBS pode ser uma alternativa para tratar este tipo de efluente.

\section{Experimentos com Reator em Batelada} Sequencial e comparação com a legislação ambiental brasileira

No Rio Grande do Sul, Brasil, os padrões de lançamento de efluentes líquidos são fixados pela Resolução do Conselho Estadual

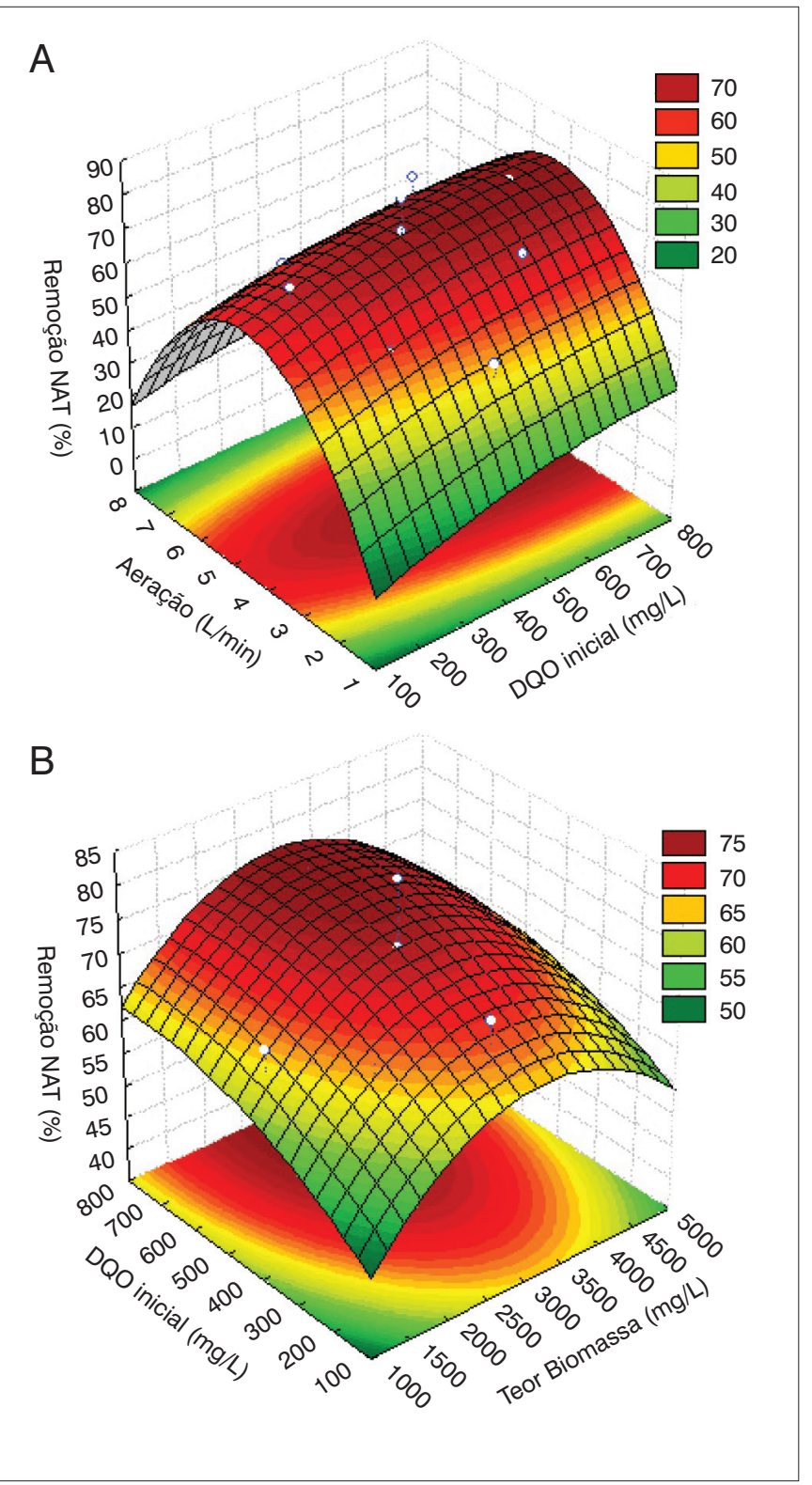

Figura 3 - Superfície de resposta para remoção de nitrogênio total Kjeldahl, utilizando as variáveis: (A) aeração e demanda química de oxigênio inicial e (B) demanda química de oxigênio inicial e concentração de Sólidos Suspensos Voláteis.

do Meio Ambiente (CONSEMA) n 128/2006. De acordo com esta resolução, o pH deve estar entre seis e nove, e a temperatura deve ser inferior a $40^{\circ} \mathrm{C}$. Ao se fazer um comparativo dos experimentos realizados com a legislação, os resultados obtidos nas análises de $\mathrm{pH}$ e T estão dentro dos limites estabelecidos.

A Tabela 3 mostra que as maiores eficiências de remoção para DQO foram alcançadas no experimento três, que utilizou concentração de SSV de $2000 \mathrm{mg} \cdot \mathrm{L}^{-1}, \mathrm{DQO}_{\mathrm{i}}$ de $600 \mathrm{mg} \cdot \mathrm{L}^{-1}$ e quantidade de aeração de 3 L.min ${ }^{-1}$, e no experimento oito, que utilizou concentração de SSV de $4000 \mathrm{mg} \cdot \mathrm{L}^{-1}, \mathrm{DQO}_{\mathrm{i}}$ de $600 \mathrm{mg} \cdot \mathrm{L}^{-1}$ e quantidade de aeração de 6 L.minn-1. Para o NTK (Tabela 4), a maior eficiência 
de remoção foi alcançada no experimento 14, que é um dos pontos axiais, com concentração de SSV de 3000 mg.L.-1, DQO de 700 mg.L.-1 e quantidade de aeração de 4,5 L.min ${ }^{-1}$.

Ao fazer um comparativo dos valores obtidos (Tabelas 3 e 4) com os valores limitados pela Resolução do CONSEMA n 128/2006 para a faixa de vazão menor que $100 \mathrm{~m}^{3} \cdot \mathrm{d}^{-1}$, pode-se perceber que todos os valores obtidos estão abaixo do limite estabelecido, comprovando a eficiência do reator em batelada sequencial para remoção de DQO e nutrientes de efluentes de processamento de brócolis. Novas pesquisas devem ser realizadas utilizando-se diferentes vegetais para comprovar a eficiência desta tecnologia para este tipo de indústria.

\section{Otimização das condições de operação do Reator em Batelada Sequencial}

Na Figura 2A observa-se que a remoção de DQO foi maior com a DQO inicial no nível superior (600 mg. $\left.\mathrm{L}^{-1}\right)$, não sendo influenciada significativamente $(\mathrm{p}<0,1)$ pela aeração. Nos níveis inferiores de aeração, independente da DQO inicial, a remoção de DQO foi superior a 60\% e a concentração de DQO final, inferior a $100 \mathrm{mg} \cdot \mathrm{L}^{-1}$, indicando que aeração no nível inferior (3 L. $\mathrm{min}^{-1}$ ) foi suficiente para que o RBS atingisse os limites estabelecidos pela Resolução Consema no 128/2006. Sabendo-se que uma vazão de 3 L. min ${ }^{-1}$ de ar é o suficiente, teoricamente, para remover cerca de 1,2 g de DQO, o nível inferior de aeração já seria suficiente para remover a DQO presente no reator e assim manter o nível de oxigênio dissolvido acima do recomendado pela literatura.

A Figura 2B mostra que quanto maior a DQO inicial, maior a sua remoção, independente da concentração de SSV, mesmo sendo observado aumento na remoção de DQO entre os níveis superior e inferior. Vale salientar que, mesmo nos níveis inferiores de concentração de SSV e DQO inicial, a remoção de DQO manteve-se acima de 50\%, indicando boas condições de operação do reator RBS. Desta forma, pode-se adotar, na operação do RBS, a menor concentração de SSV, ou seja 2000 mg.L-1. Esta prática, considerando a adoção de 3 L. min $^{-1}$ para a aeração, poderá otimizar os custos com aeração e disposição do lodo gerado.

$\mathrm{Na}$ Figura 3A pode-se observar que a remoção de NTK é maior com a aeração no ponto central, mas a DQO inicial não influenciou de forma significativa a remoção de NTK.

A Figura 3B mostrou que, mesmo sem influência significativa dos fatores estudados, a remoção de NTK foi maior com a DQO inicial no nível superior e a concentração de SSV no ponto central. Isto pode ser explicado em função de que as remoções de NTK nos pontos estudados ficaram próximos à região de máxima remoção.
A otimização das condições de operação do RBS tem que levar em consideração as remoções de DQO e NTK conjuntamente. Sendo assim, deve-se considerar o seguinte:

a) Em relação à aeração, esta não foi significativa para remoção de DQO, mas influenciou de forma significativa na remoção de NTK. Para a remoção de NTK acontecer, é preciso que haja uma maior aeração em comparação à remoção de DQO, o que justifica a utilização de níveis superiores para a remoção conjunta de DQO e NTK em um mesmo RBS;

b) Em relação a concentração de SSV, a remoção de DQO não foi significativamente influenciada pela sua variação, o que indica que não seria necessário um controle rigoroso na concentração de SSV para remoção de DQO. Para a remoção de NTK, o ponto ótimo foi alcançado no ponto central, embora este fator não tenha sido significativo $(p<0,1)$, indicando a utilização do nível inferior de SSV (2000 mg. L-1), assim como para a remoção de DQO. Essa concentração de SSV está entre os valores indicados por Sperling (1997), que diz que os valores típicos de concentração de SSV no reator variam de 1500 a $3500 \mathrm{mg} \cdot \mathrm{L}^{-1}$.

c) Em relação a DQO inicial, percebe-se que, ao se utilizar DQO inicial no nível superior houve um aumento, tanto na remoção de DQO, quanto na remoção de NTK. Isto mostra que a presença de carbono nos níveis superiores do estudo não impediu a remoção de nitrogênio. Sendo assim, a utilização de DQO inicial em níveis superiores é preferida.

Assim, as condições otimizadas para remoção de DQO e NTK de efluente de processamento de brócolis foram: DQO de $600 \mathrm{mg} \cdot \mathrm{L}^{-1}$, aeração de 4,5 L.min ${ }^{-1}$ e concentração de SSV de $2000 \mathrm{mg} \cdot \mathrm{L}^{-1}$

\section{Conclusões}

A utilização do reator em batelada sequencial é uma importante alternativa para agroindústrias, possibilitando a retirada de grandes concentrações de carbono e nutrientes dos efluentes. O RBS demonstrou ser de fácil operação e controle, além de apresentar um bom desempenho na remoção de DQO e NTK, com 88 e 74,9\% de remoção, respectivamente, o que comprovou sua aplicabilidade no tratamento de efluente do processamento de brócolis. Novas pesquisas devem ser realizadas utilizando-se diferentes vegetais para comprovar a eficiência desta tecnologia para este tipo de indústria.

As condições otimizadas para remoção de DQO e NTK de efluente do processamento de brócolis foram: $\mathrm{DQO}_{\mathrm{i}}$ de $600 \mathrm{mg} \cdot \mathrm{L}^{-1}$, aeração de 4,5 L.min ${ }^{-1}$ e concentração de SSV de 2000 mg.L $\mathrm{L}^{-1}$ 


\section{Referências}

AMERICAN PUBLIC HEALTH ASSOCIATION. (2005) Standard Methods for the Examination of Water and Wastewater. 21. ed. Washington: APHA, $1260 \mathrm{p}$.

AKIN, B.S. \& UGURLU, A. (2005) Monitoring and control of biological nutrient removal in a Sequencing Batch Reactor. Process Biochemistry, v. 40, p. $2873-2878$.

CONSEMA - CONSELHO ESTADUAL DO MEIO AMBIENTE. Resolução Consema $n^{\circ}$ 128/2006. Disponível em: <http://www.sema.rs.gov.br/ sema/html/pdf/Resolucao128Efluentes. pdf > . Acesso em: 21 nov. 2008.

COSTA, T.B. (2005) Desempenho de reator em batelada sequencial (RBS) com enchimento escalonado no tratamento de esgoto sanitário doméstico. Dissertação de Mestrado, Universidade Federal de Santa Catarina, Engenharia Ambiental, Florianópolis, 2005.
CYBIS, L.F. \& PICKBRENNER, K. (2000) Uso de reator sequencial em batelada para pós tratamento de efluentes de tratamento anaeróbio. In: Congresso Interamericano de Engenharia Sanitária e Ambiental, 27, Porto Alegre. Anais. Porto Alegre.

EPA - UNITED STATES ENVIRONMENTAL PROTECTION AGENCY. Wastewater technology fact sheet: Sequencing batch reactors. Set. 1999

KIM, Y.H.; YOO, C.K.; LEE, I.B. (2008) Optimization of biological nutrient removal in a SBR using simulation-based iterative dynamic programming. Chemical Engineering Journal, v. 139, p. 11-19.

RAMJEAWON, T. (2000) Cleaner production in Mauritian cane-sugar factories. Journal of Cleaner Production, v. 8, p. 503-510. 